\title{
HET AMENDEMENT-MARCHANT OP ART. 94 VAN DE GRONDWET VAN 1917 EN DE WEST-INDISCHE STAATSDEELEN \\ DOOR
}

DR. MR. F. M. DA COSTA GOMEZ

I

Dit amendement strekte om als vierde lid van art. 94 (oud) de volgende bepaling in de grondwet op te nemen: „Het vertegenwoordigend lichaam in Nederlandsch-Indië, in Suriname en in Curaçao kan aan een of meer zijner leden opdragen, de belangen van het gebied voor te staan in de vergaderingen der StatenGeneraal bij de behandeling van onderwerpen rakende die belangen". (Handelingen Tweede Kamer 1921/22 p. 874 -882).

In zijn toelichting bracht Marchant verschillende denkbeelden in herinnering, die geopperd waren in de Indische herzieningscommissie en in de Staten-Generaal naar aanleiding van de rede van De Savornin Lohman van 3 April 1919, waarin deze gewezen had op de gebrekkige kennis der Staten-leden ten opzichte van de Koloniën.

Deze denkbeelden hielden de volgende mogelijkheden in:

le. Afvaardiging van vertegenwoordigers der overzeesche parlementen naar de Staten-Generaal;

2e. Het in de gelegenheid stellen van leden der Staten-Generaal studiereizen te maken naar de overzeesche landen;

3e. Wijziging van de Eerste Kamer, zoodat de volksgroepen, die bijzonder belang hebben bij de ontwikkeling in Indië, haar invloed zouden kunnen doen gelden op haar samenstelling;

4e. Opname van Indische specialisten in de Tweede Kamer.

Deze denkbeelden hebben geen ingang gevonden wegens de daaraan verbonden bezwaren, die hier niet terzake doen.

„Het eenige middel dat overblijft”, zegt Marchant, ,is, dat men het Indische volk gelegenheid geeft, zelf zich in deze Vergadering te laten hooren".

„Waar we hier behoefte aan hebben, is, dat hier gehoord wordt 
HET AMENDEMENT-MARCHANT OP ART. 94 VAN DE GRONDWET 375

de levende stem van degenen, over wier belangen wordt gehandeld. Men denke zich eens in den psychischen toestand van het Indische volk, dat hier in deze Vergadering zijn belangen ziet behandelen, waarvan de levensbelangen worden beslist in deze Vergadering, en dat niettemin datzelfde volk zich niet in deze Vergadering mag laten hooren, zelfs niet met een adviseerende stem!

Men keere den toestand eens om en stelle zich eens voor, dat de belangen van Nederland zouden voorzien worden bij wetgevende maatregelen, die in Indië getroffen werden, zonder dat men daaraan kon medewerken. Het valt zoozeer in het oog, hoe onrechtmatig en onmogelijk dat zou zijn, dat ik hier de opmerking hoor, dat het geen vergelijking is.

Elke vergelijking gaat mank. Maar de positie, waarin Nederland zou zijn, indien in Indië de Nederlandsche belangen bij de wet werden geregeld door een bevolking, waarmede wij niet in rechtstreeksch contact zouden zijn, zonder onze medewerking, zonder zelfs onze adviseerende stem te kunnen doen hooren, zou in omgekeerde verhouding precies dezelfde positie zijn, als waarin het Indische volk verkeert tegenover deze Vergadering".

„Niemand kan in ernst beweren, dat deze Vergadering bevoegd is de wetgeving te maken voor Indië. Men kan dat overlaten aan de Regeering. Men is hier verplicht veel te veel over te laten. Men laat over aan de Regeering om van hieruit Indië te besturen en de wetgeving te maken voor Indië onder omstandigheden, waarop het Indische volk en zijn eigen Regeering geen invloed hebben. Daarom is het zoo noodig, dat men de levende stem van het volk zelf hier zich laat hooren, hier in de Volksvertegenwoordiging, waar ten slotte die wetten tot stand komen. Het is een zoo natuurlijk en begrijpelijk verlangen van het Indische volk, dat ik mij niet kan voorstellen, dat deze Vergadering zou weigeren aan dat verlangen, aan dien wensch te voldoen".

Tegen de verwachting van den heer Marchant zijn in de Tweede Kamer vele bezwaren gemaakt.

Dresselhuys, die de rij der sprekers opende, verklaarde sympathiek te staan tegen het voorstel van Marchant c.s. als zoodanig. Hij gaf toe, dat het in deze kamer ontbreekt aan een aantal deskundigen t.a.v. Nederlandsch-Indië. „Dat is eenmaal zoo en door het tegenwoordig kiesstelsel is het nog moeilijker geworden, dat de aandacht in Nederland op Indische specialiteiten gevestigd wordt"'. Vandaar, dat het voorstel van Marchant hem in hooge mate aantrekkelijk is. Doch: „Het amendement zegt alleen dit, 
dat de Volksraad in Indië het recht zal hebben aan één of meer van zijn leden op te dragen, de belangen van het gebied hier voor te staan bij de behandeling van onderwerpen, rakende die belangen, maar de wijze waarop, hoeveel afgevaardigden, op welke wijze zij zullen verschijnen, of zij constant hier zijn, dan wel voor speciale onderwerpen, dat alles zegt het amendement niet"'. Hierover kunnen zich moeilijkheden voordoen en daarom stelde Dresselhuys in een sub-amendement voor, alleen het beginsel in de grondwet op te nemen, dat één of meer leden van den Volksraad hier voorlichting kunnen geven, maar daarbij de reserve te maken, deze zaak later bij de wet uit te werken. Het amendement werd in dezen zin veranderd, door na het woord „kan" de woorden ,,volgens regels bij de wet te stellen" in te voegen.

Gerretson, die geen vertrouwen scheen te hebben in den Volksraad, beweerde genoeg te hebben van koloniale adviezen en adviseurs. „Wij hadden sedert [de jongste grondwetsherziening; opm. van mij] de kennismaking met de Indische adviezen èn met de adviseurs. Wij lazen de verslagen der zittingen van den Volksraad. We hoorden leden en oud-leden van dien raad. We zagen ze aan het werk - in de bekende herzieningscommissie - en we lazen ze in de pers. We kregen hier zelfs de voorstellen van den Volksraad ter beoordeeling. Dat alles heeft ons toch wel wàt geleerd ter beoordeeling van het voorstel van den heer Marchant? Mij althans doet die ervaring nog weinig sympathiek er tegenover staan. Ik zal den Volksraad niet hard vallen over menig woord en besluit dat er viel. Reeds mr. Fock vergoelijkte en zeide: ze zijn nog jong en zeggen alles wat hun op het hart ligt.

Maar ik denk hier toch aan het lang niet malsche oordeel van De Locomotief, welk Indisch blad de denkbeelden, in den Volksraad soms ter sprake gebracht, noemde: verwarring stichtende Staatkundige phantasieën.

$\mathrm{Nu}$ kennen we hier, uit droef ervaren, wat kwaad verwarring stichtende Staatkundige phantasieën inzake de Nederlandsche politiek reeds doen en dit doet niet verlangen naar een mogelijk da capo ten opzichte van de Indische politiek".

Deze tirade geeft ons aanleiding tot de opmerking, dat het mag verwonderen, waarom, indien, gelijk Gerretson zegt, de Nederlandsche vertegenwoordiging aan dezelfde kwaallijdt als de Volksraad, dan de vingers zoo gelegd worden op de gewonde plekken van den Volksraad? Eenige bescheidenheid is hier wel gewenscht. Men lette eens op hetgeen een Franschman omtrent een soortgelijk onderwerp gezegd heeft en betrachte dezelfde bescheiden- 
heid. Het ging over de verkiezings-schandalen, die plaats grepen in de Koloniën, een zeer ernstig onderwerp dus. Arthur Girault (Principes de colonisation et de législation coloniale, pag. 655, D. II) schrijft hieromtrent: „Il serait puéril de les nier. Mais il y a dans le midi de la France bien des départements qui, sous ce rapport, n'ont rien à envier aux colonies. Si, parce que, dans une circonscription électorale, le résultat des élections a été vicié par la fraude, par la corruption, par les menaces, il fallait enlever aux électeurs de cette circonscription le droit de suffrage, cela pourrait conduire singulièrement loin. Il n'y a pas que les colonies qui cesseraient d'être représentées au Parlement. Quand on veut se montrer sévère pour les autres, il faudrait tout d'abord n'avoir rien à se reprocher à soi-même. Il est excessif de s'autoriser d'un abus pour réclamer la suppression d'un droit. Il n'y a pas une seule de nos libertés publiques qui pourrait tenir contre un pareil raisonnement".

Het volgende stuk uit de rede van Gerretson klinkt zeer vreemd

„Wat ter wereld”, zoo begint deze zonderlinge passage, „hebben we nu hier aan een vertegenwoordiging van ,een of meer leden"? We krijgen dan hier een herhaling van den strijd in het vertegenwoordigend lichaam in Indië. Minstens zouden wij zeker 4 of 5 adviseurs moeten hebben. Wat nut ons dit nu? Zal het ons tot helderder inzicht brengen? Allerminst! Het zal eer velen onzer afhouden van meer ernstige, eigen vóórstudie, om het dan op dien woordenstrijd hier te laten aankomen. Met allicht nog triester resultaat! Want bij gemis van eigen inzicht, gegrond op kalm overleg na lezing van wat de Volksraad en de Indische pers en de eigen pers ons bieden, zal allicht de handigste, de welsprekendste, de meest gevatte dier afgevaardigden hier het pleidooi ook voor dit Parlement winnen".

Het komt ons voor, dat, indien dit gevaar onze Staten-Generaal in werkelijkheid gedreigd heeft, het zeer zeker beter is, dat het amendement-Marchant tijdig om hals werd gebracht. Het zou toch inderdaad geen verkwikkelijk schouwspel zijn, de handigste afgevaardigde in de Staten-Generaal te zien jongleeren met de belangen van Ned.-Indië voor de verbaasde blikken der leden en zoo hen over te halen, aan Indië te geven, hetgeen het vraagt.

Tenslotte ontwikkelde Gerretson de moeilijkheid, dat de adviseurs te langen tijd in Nederland verblijven moeten en dus het contact met Indië verliezen. Dit toonde hij aan door uit te gaan van de behandeling der begrooting. „Die afgevaardigden zullen 
dus reeds bij het afdeelingsonderzoek van die begrooting hier moeten zijn, want daarin is het zwaartepunt gelegen", zeide hij. „Die afgevaardigden zullen dus een soort wandelleeraren moeten zijn, of er zullen er steeds 5 moeten zijn voor het afdeelingsonderzoek". Deze afgevaardigden moeten de heele behandeling van het onderwerp meemaken tot en met de openbare behandeling in de Eerste Kamer. Dat vordert vele maanden.

„Maar wanneer zij hier moeten zijn bij de behandeling van de Indische begrooting, die soms wel eens pas in Februari of in Maart was afgeloopen, en zij vertrekken daarna, om weer terug te keeren bij de behandeling van een ander ontwerp, zooals bijv. het Djambi-ontwerp, dat voor Indië van veel belang is, dan zullen die afgevaardigden, steeds vice-versa reizende, te veel onderweg zijn om het Indische leven mee te blijven leven".

Gerretson zag blijkbaar de mogelijkheid over het hoofd, dat, wanneer deze afgevaardigden het contact met Indië zouden hebben verloren, en dit zou spoedig genoeg blijken, anderen benoemd zouden kunnen worden, die dit contact wel hebben! en dat in geen geval van de Staten-Generaal in hunne huidige samenstelling kan gezegd worden, dat zij dit contact hebben, ook van Gerretson niet. Daarenboven is het een gansch andere zaak of NederlandschIndiërs, Javanen of andere inheemschen afgevaardigd worden, die van oudsher met land en volk zijn vergroeid, dan wel zij, die slechts tijdelijk in Indië vertoeven, en slechts tijdelijke en geldelijke belangen daar hebben. Marchant heeft gesproken van het Indische Volk, en contact met zijn volk verliest men niet zoo gauw, als Gerretson ons wil doen gelooven. Tenslotte wees Gerretson op een merkwaardig bezwaar, n.l. dat de Indische specialiteiten zich hier zullen voelen als vreemde eenden in de bijt. „Ieder Parlement heeft zoo zijn eigen sentiment".

Misschien, had Gerretson kunnen denken, is juist dit een van de redenen, waarom Marchant zijn amendement heeft voorgesteld, misschien, dat juist tégen deze eigene mentaliteit moet gewaakt worden, en wie zouden dit beter kunnen doen dan zij, over wier belangen wordt beslist.

Na Gerretson kwam het kamerlid Scheurer aan het woord. Inleidend betoogde hij, dat de idee, dat moederland en koloniën saam één Rijk vormen, behoort tot de heidensch-Romeinsche en revolutionnaire begrippen, die geen antirevolutionnair kan en mag aanvaarden, en dat Indië zijn eigen leven heeft, dat zich in de toekomst als een eigen staatkundig leven moet ontwikkelen. 
Volgens hem lag de beste verbinding met Indië in de verslagen van den Volksraad.

Wij merken hierbij op, dat het amendement-Marchant deze adviezen niet wilde afschaffen, doch aan Indië de gelegenheid bieden, mondeling zijn belangen in de Staten-Generaal te behartigen, hetgeen een geheel verschillende zaak is, o.i. is de gedachten, dat de levende stem gehoord wordt van hen, over wier belangen beslist wordt, het staatkundig moment van het amendement.

Het kamerlid Scheurer ontwikkelde voorts bezwaren tegen de keuze van afgevaardigden door een meerderheid. De StatenGeneraal zouden tengevolge der meerderheidskeuze eenzijdig worden voorgelicht. Indien meerderheid en minderheid numeriek vrijwel tegen elkaar opwegen, zou men beide Partijen aan het woord moeten laten in de Staten-Generaal en dan ,zou men in deze Vergadering, waar het toch al aan strijdlust niet ontbreekt, menig felbewogen voorspel van dien aard tusschen onze koloniale voorlichters kunnen genieten ...." en dan vreesde spreker ,dat wij ten slotte in menig geval aan het einde van de "voorlichting" het spoor nog meer bijster zouden zijn dan aan het begin".

Misschien dat de volgende niet onvermakelijke schildering uit des sprekers rede aan dezen vrees is te wijten. „De afstand van Indië tot Nederland" zeide spreker ,is groot, de reis is van langen duur en - de ondervinding leert het aan bijna iederen Indischman - de toetsing aan Westersche toestanden en denkbeelden werken in vele gevallen met verrassend effect. De ijverige kampvechter voor een beginsel of een maatregel, die daar ginds met de meerderheid in den Volksraad hem voortreffelijk voorkwamen, wordt hier vaak in korten tijd in zijn overtuiging geschokt. De scherper afgeteekende maatschappelijke vormen en indrukken in het Westen verdringen vaak al gauw wat in het Oosten onfeilbaar werd gedacht.

Zal nu de afgevaardigde, die met volle instemming zee koos als vertegenwoordiger van de meerderheid, hier in de Staten-Generaal onder die omstandigheden tegen zijn nieuwe overtuiging in aan het Indische vaandel trouw moeten blijven? Zal hij, gedachtig aan zijn mandaat, in deze Vergadering moeten verkondigen en verdedigen wat hij zelf niet meer gelooft? De goede trouw tegenover zijn lastgevers zou het vorderen; de goede trouw tegenover de Staten-Generaal en tegenover zich zelf zou het verbieden"

Hier wordt gesproken over iets, dat ook kan geschieden met de leden der Staten-Generaal, dat men van overtuiging verandert. 
Doch wat bij uitzondering den leden der Staten-Generaal overkomt, wordt als regel voor den „Indischman” aangenomen. Hier wordt ons een zeer onaantrekkelijk beeld opgehangen van den Indisch-man, en wij vragen ons af, wie nu gerekend moet worden tot deze categorie van menschen, die zoo wankel in hun overtuiging staan, dat zij door een reis en het vertoeven in het Rijk uit hoofde van hun functie, zoo spoedig in een dergelijk conflict komen, dat hun den eisch der goede trouw moet worden voorgehouden. Aangezien uit des sprekers rede de belangrijke conclusie moet worden getrokken, dat de „Indischman" onbetrouwbaar is, ware het meer dan een eisch van billijkheid, dat de spreker deze categorie nader had omschreven, en de moeilijkheid: wie niet moet worden afgevaardigd, zou dan opgelost zijn.

Verder besprak Scheurer het gevaar, dat de deputatie zou uitdijen tot een respectabel college, waarvan de uitrustings- en verblijfkosten zwaar op het koloniaal budget zouden drukken, en dat voor de begrooting wel permanent een deputatie uit Indië aanwezig zou moeten zijn, en nog eenige technische bezwaren, die zeer wel door de wet geregeld hadden kunnen worden, zooals Dresselhuys had voorgesteld in zijn amendement.

Van Rijckevorsel meende, dat dit amendement niet paste in het systeem der grondwet, die geen rechtstreeksch contact tusschen vertegenwoordigende lichamen van verschillend karakter kent. De tegenwoordige ontwikkeling van Indië geeft geen aanleiding het systeem van de Grondwet voor Indië te breken.

„Nu kan ik mij zeer wel voorstellen”, zeide Van Rijckevorsel, „dat er een stadium van ontwikkeling van Indië, van Suriname en van Curaçao komt, waarbij de toestanden zoo veranderen, dat wij met het systeem onzer Grondwet moeten breken. Zien wij om ons heen, dan ontwaren wij, dat in het Britsche Rijk voor een deel van de koloniën, de Dominions, een zoodanig stadium is bereikt en nieuwe lichamen worden geschapen om met nieuwe toestanden rekening te houden, maar dan is het de vraag of het daarin moet worden gezocht, dat men het Parlement, de StatenGeneraal van het moederland, gaat veranderen en daarin nieuwe elementen brengen". Voor de tegenwoordige tijd zou volstaan kunnen worden met de koloniale adviezen.

In deze, gelijk in de door de andere leden gehouden redevoeringen, is geen rekening gehouden met het verschil van het WestIndische en Oost-Indische staatsdeel. Zeer typeerend is in dit opzicht de rede van den laatsten spreker, Ruys de Beerenbrouck, destijds Minister van Binnenlandsche Zaken. 
De Minister verklaarde, dat de regeering ook tegen het gewijzigde amendement-Marchant overwegend bezwaar had. „Het is immers niet te ontkennen”, aldus de Minister, „dat die door de vertegenwoordigende lichamen van Indië, Suriname en Curaçao aangewezen leden hier zouden spreken zonder dat de Indische Regeering de gelegenheid zou hebben tegenover de meening van die leden de hare te stellen. Dat lijkt mij toch wel een niet gering bezwaar. Want voor een dergelijke semi-officieele behartiging van de belangen van zulke afgevaardigden is, dunkt mij, naast de koloniale Regeering en de in Nederlandsch-Indië, Suriname en Curaçao gevestigde vertegenwoordigende lichamen geen plaats. Vertegenwoordiging toch in Nederland van een lichaam, dat deel uitmaakt van het wetgevend apparaat in Indië, zou naar het oordeel van de Regeering een hoogst zonderlinge Staatsrechtelijke figuur zijn".

De Minister vergat erbij te vermelden welke staatsrechtelijke figuur het zou geven, indien het wetgevend lichaam van Curaçao en Suriname in Nederland vertegenwoordigd zou worden.

De Minister ontwikkelde verder het bezwaar, dat de Nederlandsch-Indische Regeering zou worden verzwakt en de invloed van den Volksraad zou worden geschaad. De afgevaardigden zouden verplicht zijn hier lang te blijven en van de Indische toestanden min of meer vervreemden. „Op den duur zouden bovendien die afgevaardigden zich gaan beschouwen als de vertegenwoordigers van Indië in ons land, een centraal punt als het ware, waar men alle klachten en grieven zal aanbrengen. En juist met het oog op den Volksraad vraag ik of het gewenscht is, hier als het ware een kleineren Volksraad in het leven te roepen, die in de Nederlandsche Staten-Generaal zal zijn geïncorporeerd, ten nadeele van den Indischen Volksraad, die toch het orgaan moet zijn waarvan de Regeering de wenschen en verlangens der bevolking verneemt".

Wij merken hierbij op, dat door de positie van den Minister van Koloniën de positie der Indische regeering is verzekerd tegenover de afgevaardigden. De invloed van den Volksraad zal eerder vermeerderen dan verminderen, de afgevaardigden zijn immers leden van den Volksraad; zij vormen een deputatie van den Volksraad en zijn gebonden aan hun mandaat.

Marchant heeft zijn amendement niet kunnen redden, door het overnemen van het sub-amendement. In zijn repliek heeft hij terecht gewezen op de bedenkelijke wijze, waarop over de Volksraad en de Indische bevolking is gesproken. 
„Er wordt met minachting gesproken over den Volksraad, over de leden van den Volksraad, over de bekwaamheden van den Volksraad, over de Indische Herzieningscommissie, over het Indische volk".

Hij protesteerde vervolgens over de wijze waarop Van Rijckevorsel en de Minister deze quaestie behandelden.

„Die heeren zeggen tegen het Indische volk: „het spijt mij wel, maar het past niet in het systeem van onze Grondwet! Is dat een manier om hier de zaken te behandelen: het is nieuw, dus kan het niet? Is dat een vraag, die hier aan de orde mag zijn, waar wij te doen hebben met een volk, waarvan de belangen aan ons zijn toevertrouwd, waarvoor wij verantwoordelijk zijn? Dat volk vraagt eigen rechten, vraagt ons, hier zijn stem te mogen laten hooren; de heer Van Rijckevorsel en de Minister antwoorden: het past niet in het systeem van onze Grondwet, het is nieuw, wij hebben met uw wenschen niet te maken. Maar is dat een standpunt, dat deze vergadering kan innemen? Die tijd is voorbij. Aldus wekt men opstand in Indië".

Wij voegen hier nog aan toe, dat Scheurer en Gerretson in hun dupliek aan Marchant verklaard hebben, niet met minachting over den Volksraad te hebben gesproken. Uit hetgeen wij echter hebben medegedeeld blijkt, dat, wanneer dit niet als zoodanig bedoeld was, de door deze leden gehouden redevoeringen niettemin opmerkingen bevatten, die zeer onaangenaam aandoen.

Ruys de Beerenbrouck hield het bezwaar staande, dat het college der afgevaardigden een tweede Volksraad zou worden. Echter is er, zooals wij boven opmerkten, geen reden dit a priori aan te nemen.

Zoo viel het sympathieke amendement van den verzienden staatsman Marchant met 30 tegen 29 stemmen. De hoop van den heer Scheurer, dat dit gewijzigde amendement met de grootst mogelijke meerderheid zou worden verworpen, is dus niet in vervulling gegaan.

Hoe langer hoe meer is het gewoonte geworden, het onderscheid tusschen Oost- en West-Indië kunstmatig te vervagen. De Kamers en de regeering zijn in dit opzicht evenwel op een verkeerden weg.

De behandeling van het amendement-Marchant levert een sprekend voorbeeld van onjuistheden, die begaan werden tenge- 
volge van de verwaarloozing van de scheidingslijn tusschen Oost en West. Zoo is aan het eigen wezen van de West-Indische staatsdeelen geen aandacht geschonken, en hadden bezwaren tegen de toekenning van een staatsrechtelijke instelling aan de Oost, welke echter niet bestonden tegen de toekenning van dezelfde instelling aan de West, niettemin voor beiderlei gebiedsdeelen hetzelfde effect.

De argumenten, die de sprekers hebben aangevoerd tegen het amendement-Marchant zijn alle ontleend aan omstandigheden betreffende Nederlandsch-Indië. Het is opvallend, dat geen enkel argument, dat tegen het zenden van afgevaardigden van de overzeesche parlementen naar de Staten-Generaal is aangewend, t.a.v. de West-Indiën juist is; men denke aan de langdurige reis, de begrooting en, last not least, aan den Indischman, de psychologie van den Indischman geheel daargelaten. Ik zal dan ook niet verder op deze argumenten ingaan, doch mij beperken tot een waardeering van dit amendement in verband met den staatrechtelijken toestand van de West-Indische koloniën.

Het doel van dit amendement was: te voorzien in de gebrekkige kennis der Staten-Generaal omtrent de overzeesche gebieden. Deze doelstelling is juist. De gebrekkige kennis van de Statenleden is herhaaldelijk ten aanzien van de West-Indiën aan den dag gekomen en vooral ten aanzien van Curaçao.

Het amendement trachtte het gestelde doel te verwezenlijken door middel van afgevaardigde leden der overzeesche parlementen; dus wanneer dit heden moest geschieden, door middel van één of meer afgevaardigden van de Staten van Suriname of van den Kolonialen Raad van Curaçao, en, wanneer Curaçao binnenkort zijn wet op de staatsinrichting verkrijgt, van de Staten van Curaçao.

Ik zal ter vereenvoudiging de vraag naar de orgaan-qualiteit dezer lichamen niet stellen, m.a.w. niet ingaan op de vraag of deze werkelijk de wil van het Surinaamsche en het Curaçaosche volk openbaren, zoodat de leden van de Staten-Generaal inderdaad de levende stem van het volk eventueel hadden kunnen vernemen. Slechts willen wij hierbij opmerken, dat de Koloniale Raad in zijn huidige samenstelling niet als een volksorgaan kan worden beschouwd. Ik beperk mij tot deze vraag: Was het amendement-Marchant in overeenstemming met de staatsrechtelijke verhouding van het Rijk tot Suriname en Curaçao?

Het zij mij geoorloofd de contouren van de staatsrechtelijke verhouding van het Rijk tot de West-Indische staatsdeelen beknopt weer te geven. 
Krachtens art. 1 van de Grondwet van 1922 is het West-Indisch territoir, staatsterritoir. Hoezeer ook de opvattingen omtrent de draagwijdte van art. 1 van deze Grondwet uiteenloopen, vast staat, dat de genoemde territoria zijn gelijkgeschakeld. Het karakter van de W.I. staatsdeelen wordt derhalve bepaald door het bezit der staatsburgerschapsrechten der inwoners dezer gebiedsdeelen. De wet van 1892 op het Nederlanderschap bepaalt $\mathrm{nu}$, dat de bewoners der W.I. gebiedsdeelen Nederlanders zijn. Door deze wet worden de staatsburgerschapsrechten van de bewoners dezer gebiedsdeelen gelijk aan de burgerschapsrechten van de bewoners van het Rijk, natuurlijk altijd met uitzonderingen t.a.v. het ingezetenschap. Er bestaat één staatsterritoir en één gelijke staatsaanhoorigheid, en dus één eenheidsstaat: de Nederlandsche Staat, waarvan de West-Indiën deel uitmaken. Deze staat, die geconstrueerd is uit het Rijk, Suriname en Curaçao, bezit een volksvertegenwoordiging in de Staten-Generaal. Terecht zegt art. 79 G.W., dat zij het geheele Nederlandsche volk vertegenwoordigen. Onder het geheele Nederlandsche volk moeten de staatsburgers in de West-Indiën worden begrepen, daar na de wet van 1892 op het Nederlanderschap deze bepaling onveranderd is gebleven. Een verwijzing naar art. $2 \mathrm{G}$.W. is geen argument tegen deze opvatting, omdat de Grondwet ter bepaling van wie Nederlanders zijn verwijst naar de wet, en deze wet de West-Indiërs in de Nederlandsche volksgemeenschap heeft opgenomen. Een argument tegen deze opvatting kan ook niet gevonden worden in de wet op het onderdaanschap, die in 1927 ten onrechte tot de West-Indiën is uitgebreid; immers, deze wet regelt het onderdaanschap van niet-Nederlanders in deze gebiedsdeelen. $\mathrm{Zij}$ is een aanvullingswet op de wet van 1892 . Zooals bekend, zijn in de wet van 1892 talrijke leemten, waardoor personen, die volgens deze wet eigenlijk Nederlanders moesten zijn, apatriden of vreemdelingen werden. Deze consequenties zijn te wijten aan de onjuiste (onjuist in verband met de overgangsbepaling) redactie van art. 1 en 2, waarin als plaatsbepaling is opgenomen het Rijk, en niet het Rijk of deszelfs koloniën. T.o.v. personen, die in gelijke omstandigheden verkeerden, ontstond verschil van nationaliteit bijvoorbeeld ten opzichte van vondelingen. Een in het Rijk te vondeling gelegd kind is Nederlander, terwijl een in Curaçao of Suriname te vondeling gelegd kind apatride is, niettegenstaande het feit dat krachtens de overgangsbepaling de wet van 1892 ook voor Curaçao en Suriname geldt. Een en ander valt te meer op, omdat in het onderhavige geval vondelingen krach- 
tens het B.W. noch in het Rijk noch in Curaçao of Suriname Nederlanders waren. Ten gevolge van art. $2 b$ werden vondelingen in het Rijk Nederlanders, in de genoemde gebieden evenwel niet.

Ik geloof niet, dat de wetgever deze consequenties voor oogen gehad heeft, want het is zonder meer duidelijk, dat het onderscheid onbillijk is en ten onrechte wordt gemaakt. Ten gevolge van de onjuiste redactie van art. 1 en 2 zijn nóg natuurlijke en verlaten kinderen en kinderen van aldaar gevestigde vreemdelingen en hunne afstammelingen apatriden of vreemdelingen gebleven. De bedoeling van de wet van 1927 kan voor Curaçao en Suriname geen andere zijn dan in de genoemde leemten der wet van 1892 te voorzien. De wijze, waarop de wetgever in de gebreken van de wet van 1892 heeft voorzien, is onlogisch en ten eenen male onjuist. Onlogisch, omdat een aanvullingswet hetzelfde beginsel moet huldigen als de hoofdwet, waarvan zij een aanvulling is. Onjuist, omdat zij in strijd is met de op West-Indië toegepaste staatkunde; omdat het onderdaanschap een technisch begrip is, toegepast op de bevolking van Ned.-Indië; omdat zij onderscheid brengt in de bevolking; omdat haar psychologische werking verkeerd is, en omdat de West-Indische bevolking haar stellig niet wenscht.

Ik zal hier verder op deze wet niet ingaan, omdat ik meen voldoende gewezen te hebben op het karakter van de wet van 1927 op het onderdaanschap als aanvullingswet, die het hoofdbeginsel van de staatsaanhoorigheid van de West-Indiën niet aantast.

Staat vast, dat de West-Indische volken in werkelijkheid zijn opgenomen in de Nederlandsche volksgemeenschap en dat de Staten-Generaal de vertegenwoordiging zijn van den geheelen Nederlandschen Staat, die de belangen van het geheele Nederlandsche volk moeten behartigen, dan staat ook vast, dat het geheele Nederlandsche volk aan deze vertegenwoordiging in werkelijkheid moet deelnemen.

Hier komt nog bij, dat binnen deze staatsrechtelijke eenheid ook bestaat de eenheid van de Nederlandsche wetgeving, zoodat de juridische aansluiting aan het moederland als nagenoeg voltooid kan worden beschouwd.

$\mathrm{Nu}$ bestaat er binnen het Staatsrecht van het Rijk, als deel van den Nederlandschen Staat, niet een drievoudige vertegenwoordiging van hetzelfde belang, en het zou bijzonder onelegant, geheel ongebruikelijk en ontoelaatbaar zijn, dat vertegenwoordigers der lagere rechtsorganen de belangen van hun ressort in de Staten-Generaal kwamen bepleiten. Het zou m.i. even zonderling 
zijn binnen de aangeduide contouren van den Nederlandschen Staat voor de West-Indische staatsdeelen dezelfde onelegante drievoudige belangenvertegenwoordiging te aanvaarden, nu de Staten-Generaal ook de West-Indische vertegenwoordiging vormen. Daar het van den anderen kant ook zeker is, dat de Rijkswetgever niet binnen afzienbaren tijd het kiesrecht zoo zal wijzigen, dat tot de samenstelling van de Staten-Generaal ook de West Indiërs zullen medewerken, moet de oplossing elders gezocht worden. De oplossing, die m.i. dan het beste voldoet moet gezocht worden in de delegatie van macht.

De Staten-Generaal vormen de vertegenwoordiging van het W.-Indische volk. Indien zij niet in staat zijn de locale belangen te behartigen tengevolge van tijdgebrek of onvoldoende kennis der betrokken staatsdeelen, dan zullen zij in beide gevallen hun bevoegdheden billijkerwijze moeten delegeeren aan de locale vertegenwoordigende rechtsorganen der overzeesche Nederlandsche staatsdeelen, die beter in staat zijn de plaatselijke belangen te behartigen. Het algemeen vertegenwoordigend wetgevend orgaan der West-Indische staatsdeelen, de Staten-Generaal, kunnen zich bepalen tot het aangeven der algemeene directieven en tot het regelen van hetgeen gerekend kan worden tot de algemeene staatsbelangen.

In dezen zin is art. 61 van de Grondwet veranderd.

28 November 1935. 